\title{
[ The Wolf in American Environmental Literature: predator or scapegoat? ]
}

\section{Pavel Šefraný}

University of Ostrava, Ostrava,

Czech Republic

[Abstract] The chief focus of this paper is to discuss the presence of the wolf in American environmental literature of the $20^{\text {th }}$ and $21^{\text {st }}$ centuries. This animal has been portrayed many times in literary works by American writers, be it fiction or non-fiction, and it is the subject of numerous opinions, some of which are biased, others objective, but all intriguing and more connected with the human way of life than would at first seem to be the case. The first part of this text presents an insight into the topic through examples from American literary fiction. It studies the depiction and presence of the wolf in American environmental literature of the last two centuries, before discussing a categorization of this animal's portrayal in American literature. The topic of the presence of the wolf in American literature is examined through a comparison of its depictions in both environmental and fictional works.

[Keywords] wolves; ecocriticism; American environmental literature; mythology; endangered species; wilderness conquest; Barry Lopez;

S. K. Robisch; Cormac McCarthy; Jack London

This text is a result of the project SGS04/FF/2019 "Ecocritical Perspectives on $20^{\text {th }}$ and $21^{1 t}$-Century American Literature" supported by the internal grant scheme of the University of Ostrava. 


\section{[1] Introduction}

I have looked for a wolf different from that ordinarily given us in the course of learning about animals. I have watched captive wolves in Barrow, Alaska; in Saint Louis, and in Nova Scotia. I drove across the Dakotas and Montana and Wyoming, speaking with old men who killed wolves for a living when they were young. In New York I read in libraries like the Pierpont Morgan what men thought of wolves hundreds of years ago. I read in the archives of historical societies of outlaw wolves and Indians. I went out with field biologists in Minnesota and Alaska and spoke with Eskimos. I spoke with people who loved wolves and with people who hated them. I remember sitting in this cabin in Alaska one evening reading over the notes of all these encounters, and recalling Joseph Campbell, who wrote in the conclusion to Primitive Mythology that men do not discover their gods, they create them. So do they also, I thought, looking at the notes before me, create their animals. (Lopez 6)

When writing this article about an animal that is so widely present in humanity's culture and history - not only in the United States, but also in all the major cultures across the globe - it seemed fitting to begin with the above-cited excerpt from a book by Barry Lopez, Of Wolves and Men (1979), as it aptly sets out the article's theme. The article will explore the roles the wolf plays in both fictional and environmental writings, and it will investigate how people perceive and portray wolves in their everyday lives, stories and myths. I will focus on the representation of this animal by humans, exploring myths, fairy tales, prejudices and exaggerated glorifications of the wolf. The works taken into consideration range from environmental essays and texts by Aldo Leopold, Barry Lopez and Gary Snyder to novels by Jack London or Cormac McCarthy. After surveying literary depictions of the wolf in both fictional and environmental works, the paper categorizes portrayals of the wolf in literature using a typology outlined in the works of Barry Lopez and Sean Kipling Robisch.

The paper will attempt to unravel the many facets of the wolf and its place in American environmental literature in order to seek similarities or differences in the ways of depicting this animal within the American literary tradition.

\section{[2] The wolf in American fiction}

I begin by illustrating the portrayal of the wolf, starting with works of fiction. The first author to mention in this regard is Cormac McCarthy. In McCarthy's novel The Crossing (2001), a part of his so-called Border Trilogy, the wolf and the decline of this species plays a significant role. In the novel, the decline of the wolf population in New Mexico represents man's desire to take control over the natural world. As wolves are considered predators, man tries to intervene and cull them in order to protect himself and his property. This action has a direct impact on the absence of wolves in the wild. To explain the historical context of the novel, Wallis Remsen Sanborn's article "I Aint Heard One in Years”: Wolves as Metaphor in “The Crossing” - taken from The Cormac McCarthy Journal 
(2003) - is of relevance, as it describes how the rivalry between man and wolf in Europe has been present for a very long time. This theme can be already observed in the pictographs dating from around $13000 \mathrm{BC}$ in the caves in Dordogne, France. The depiction of a wolf as an evil creature persisted, and this animal was mythologized by people on a large scale (Sanborn 25-26).

In The Crossing, however, McCarthy portrays the wolf not only as a part of the landscape, but also as an individual that communicates various messages. It is actually a wolf's howl that launches the story and enables the main character, Billy Parham, to track a pack of seven wolves hunting an antelope. After lengthy eye contact between the pack and Billy, he practically starts to feel an internal struggle over the vanishing-breed myth.

The wolf population was in significant decline in the Southwest at the end of the 1930s, and a she-wolf, which plays an important role in the story, crosses the international border. She does this for the first time, as she has become isolated from her pack and needs to find the other wolves. However, she only finds a dead game carcass, and no trails of the pack, and thus she becomes the only wolf character in the novel, leaving us with no clarification of what happened to the rest.

Billy, having experienced a poetic encounter with the other wolves, tries to imagine the connection between the she-wolf and the pack; many times in the novel he attempts to understand it, with a kind of sorrowful obsession. As Robisch describes these events in his Wolves and the Wolf Myth in American Literature (2009): "He closed his eyes and tried to see her. Her and other of her kind, wolves and ghosts of wolves running in the whiteness of that high world as perfect to their use as if their counsel had been sought in the devising of it" (176).

Nevertheless, his father decides to trap the she-wolf and Billy accepts this task, but his mental vision of the wolves and his readiness to help his father kill her stand in a kind of contrast to each other. He tries to catch the she-wolf with the attitude of a hunter, rather than a killer. At this time, Billy does not realize his wish to preserve the wolf, so he feels the pleasure of the hunt, which is to end in a form of obsession over the animal.

During this hunting struggle, Don Arnulfo, an old man, tries to emphasize the mystery of this animal: "The wolf is an unknowable thing. What is caught in the trap is no more that teeth and fur. The wolf itself cannot be known" (McCarthy 218). He also talks about how impossible it is to trap the animal: "The wolf is like the copo de nieve...You catch the snowflake but when you look in your hand you don't have it no more. Maybe you see this dechado. But before you can see it. If you want to see it, you have to see it on its own ground. If you catch it you lose it" (180).

The old man points out the spiritual nature of the animal and the irreparable loss of the species, hunted to extinction. All these factors encourage Billy to change his mind for good, in spite of his father and the community, and he decides to save the wolf instead of killing her. His observation of the animal, when he tries to lead the wolf to her kind, is an attempt to see the wolf in its own realm.

As the mutual relationship between civilization (mankind) and the wild (represented by the wolf) has so far been mainly examined from the point of the view of the former, 
the writings of Jack London could bring a perspective on the latter. The following paragraphs discuss two of London's texts, White Fang (2014) and The Call of the Wild (2011), which deal with the theme of wildness in wolves and dogs living on the dividing line between nature and humanity.

The principal theme of White Fang (2014) is the difference between life in the wilderness and life in the company of humans. The main protagonist, after whom the book is named, is a wolfdog born in the wild. His life in the pack, where he stands apart due to his mixed heritage, is one of dire struggle: "The Wild still lingered in him and the wolf in him merely slept" (158). The brutal conflict and fight for survival on a daily basis is initially synonymous with White Fang's existence and mirrors the true wild life of the wolf pack: "White Fang knew the law well: to oppress the weak and obey the strong" (87). This survival of the fittest, however, is not the sole motive in the life of the pack. Another important aspect is the aim of a wild animal's life:

The aim of life was meat. Life itself was meat. Life lived on life. There were the eaters and the eaten. The law was: EAT OR BE EATEN. He did not formulate the law in clear, set terms and moralize about it. He did not even think the law; he merely lived the law without thinking about it at all. (59)

This simple yet harsh code is presented as the core of the wolf's life. London depicts the life of the pack, and by extension the life of wolves in general, as a rather bloody and drastic world. In this reality, the victors emerge at the expense of the vanquished, the predator to the detriment of the prey. Nevertheless, the notion of evil is expressly denied in these images. London clearly claims that the cruel world of the pack, which may give people an impression of an unfair and pitiless hell for those who cannot fight for themselves, is the ultimate way of nature. The animals themselves simply do what they must to survive, with no ulterior motive and no hatred. Unlike humanity, they are simply incapable of such a stance:

He became quicker of movement than the other dogs, swifter of foot, craftier, deadlier, more lithe, more lean with ironlike muscle and sinew, more enduring, more cruel more ferocious, and more intelligent. He had to become all these things, else he would not have held his own nor survived the hostile environment in which he found himself. (80)

This hard natural life, where the pack looks out for its members and has to deal with difficulties at every turn, is set in opposition to the world of man. The author utilizes a comparison with the life of domesticated animals, as White Fang can experience for himself the difference between the two realities: "To have a full stomach, to daze lazily in the sunshine - such things were remuneration in full for his ardours and toils, while his ardours and toils were in themselves self-remunerative. They were expressions of life, and life is always happy when it is expressing itself" (59-60). We see that the wild side of the animal still remains intact. The author, in the persona of his protagonist, ponders on the luxurious and comfortable life with humans. London here expresses the idea that the rewarding moments of peace and leisure are comparable to the feeling the wolf gets from 
its struggle and toil, as it is in the wolf's nature to fight on and so he does not view this reality in the same way as man does.

London then further depicts the relationship between man and animals in the following way: "Food and fire, protection and companionship, were some of the things he received from the god. In return he guarded the god's property, defended his body, worked for him, and obeyed him" (91). We see that animals view man in a similar way to that in which people view gods. But London does not present this relationship as one of simple blind obedience; rather, he shows it as a mutually beneficial partnership. In this particular situation, the wolf is no servant to man, but a voluntary helper who receives the protection and warmth of fire at the place where man lives. This relationship is far more similar to that found in a pack hierarchy, where the wolf obeys his alpha for the benefit of the pack and for his own benefit, than the complete obedience and undying loyalty of a dog. This fact indicates that the wildness in the protagonist has never been rooted out, not even by domestication. And his ferocious side, which stirs in times of need, is ultimately what saves the life of one of his owners at the estate where he lives for the rest of his days.

If White Fang is the story of a wild animal that grows accustomed to living with man, then London's The Call of the Wild essentially depicts this situation in reverse. In the book, we meet a domesticated dog named Buck, a Scotch Shepherd/St. Bernard cross-breed. This dog gradually leaves the society where he was raised; at the very end of the novel, he joins a pack of wolves, and in doing so answers the call of the wild. The major theme of the book is that the dormant wild side is to be found even in an already-domesticated animal, which by extension gives humanity a clear message: when forced to live again in harsh conditions, in the natural world, the wild side instinctively emerges in order to help with survival.

Buck's passage into the wild comes gradually. Initially he experiences the struggle of nature through the relationships in a pack of sledge dogs: "He had been suddenly jerked from the heart of civilization and flung into the heart of things primordial" (London, Call 15). Although this situation merely mimicked a real fight for survival, it still represented a shock for a domesticated animal, which quickly understood that in order to survive and thrive, its mindset must change. This change comes instinctively to Buck:

The first theft marked Buck as fit to survive in the hostile Northland environment. It marked his adaptability, his capacity to adjust himself to changing conditions, the lack of which would have meant swift and terrible death. It marked, further, the decay or going to pieces of his moral nature, a vain thing and a handicap in the ruthless struggle for existence. (21)

While White Fang understood the brutality of life with stoic acceptance and took these realities to be a normal occurrence, Buck's point of view is somewhat more traumatic and shocking, as he is forced to acclimatize quickly to this new way of life. However, his initial shock is accompanied by an immense sense of wonder and mystery. This instinctive urge - which, much to the dog's surprise, was already in him - calls out to 
him. London expresses once again the notion that life in the wild, which man may see as unforgiving, has its own appeal for animals:

Deep in the forest a call was sounding, and as often as he heard this call, mysteriously thrilling and luring, he felt compelled to turn his back upon the fire and the beaten earth around it, and to plunge into the forest, and on and on, he knew not where or why; nor did he wonder where or why, the call sounding imperiously, deep in the forest. (62)

In the end, the dog Buck ends up not only living with a wild pack of wolves in the forest; he also asserts his dominance and claims the position of the alpha male in the pack. In order to do so, the author emphasizes that even an animal that is initially docile in comparison with a feral wolf can return to its roots in such a manner that it asserts its leading position in the harsh society of wolves. By the end, the way in which the dog behaves, thinks and lives is strongly reminiscent of the beginning of White Fang's story:

He must master or be mastered; while to show mercy was a weakness. Mercy did not exist in the primordial life. It was misunderstood for fear, and such misunderstandings made for death. Kill or be killed, eat or be eaten, was the law; and this mandate, down out of the depths of Time, he obeyed. (62)

While Jack London's novels definitely offer a somehow idealized view of these animals and convey their way of life in the form of adventurous episodes, they still offer a profound insight into the mind of wolves and their relationship with man. This is especially so when the reversed stories of the two above-mentioned books and their protagonist animals are taken into account.

\section{[3] The wolf in American environmental literature}

As has been discussed above, the wolf is an intelligent and mysterious animal which some know and recognize for its value to the environment, yet at the same time there is a significant portion of society that would remove it from the land. We have seen portrayals of this in some American literary works of fiction, but what is the portrayal of this animal in American environmental literature? The merit of studying these predators presents ecocriticism with a variety of important topics and forms a significant part of Animal Studies.

To begin, it is necessary to mention one of the principal qualities that the wolf represents in many environmentalist texts, and that is its association with the wilderness, the untamed and uncolonized virgin land, both dangerous and beautiful. As Gary Snyder mentions in his Practice of the Wild (1990), wild and good should not be viewed as qualities on two different sides of the fence. Snyder actually encourages the sort of reliance on our "wild side", on our instincts and intuition, on co-existence with the wild and the natural, that is often represented by the wolf in his writings and those of others. He also 
emphasizes our ability to choose whether we learn the rules of civilized society or maintain the wild side of ours:

Yet there is such a thing as training. The world moves by complementaries of young and old, foolish and wise, ripe or green, raw or cooked. Animals too learn self-discipline and caution in the face of desire and availability. There is learning and training that goes with the grain of things as well as against it. In early Chinese Daoism "training" did not mean to cultivate the wildness out of oneself, but to do away with arbitrary and delusive conditioning. (Snyder 91-92)

Apart from Snyder's belief that there is no necessity to erase our "wild side" by education, he also points out that even wild animals themselves are able to exert self-discipline and control their wild impulses if the need arises. This similarity between mankind and the animal kingdom is another reason not to erase the wilderness altogether, but rather to find a mode of co-existence with it.

This point of view is present in Snyder's work too, as he argues that the preservation of wild predators, wolves included, is of paramount importance: "The deer and all the other animals move through with the exception of Grizzly bear and wolf; they are temporarily not in residence in California. We will someday bring them back" (Snyder 102-103).

Another author who approaches the topic of the wild wolf is Gretel Ehrlich, in her The Solace of Open Spaces (1986) Here there is one essay in particular, "Friends, Foes, and Working Animals", which explores the relationship between man and animals. Sheepdogs in particular are of interest in this essay, as they form a bridge between wolves and man. Ehrlich describes how we have stronger and more sincere relationships with these animals than with any other farm-domesticated animals, which could be attributed to the pack and the companionship we share, much like wolves do (Ehrlich 63-64).

Ehrlich's lines can be also read with special attention to how people harness the ferocity and wild instincts still lying dormant within dogs, as she writes:

Dogs who work with sheep have to be gentler than cowdogs. Sheep are skittish and have a natural fear of dogs, whereas a mother cow will turn and fight a dog who gets near her calf. If kelpies, border collies, and Australian shepherds cower, they do so from timidness and because they've learned to stay low and out of sight of the sheep. With their pointed ears and handsome, wolfish faces, their resemblance to coyotes is eerie. But their instinct to work sheep is only a refinement of the desire to kill; they lick their chops as they approach the herd. (Ehrlich 65)

Among the environmental texts presenting the direct confrontation between wolf and man is $A$ Sand County Almanac: And Sketched Here and There (1989) by Aldo Leopold. This collection of essays deals with more than one environmental topic and focuses on the idea of interconnections within the ecosystem. The following lines offer an illustration of these ideas:

In those days we had never heard of passing up a chance to kill a wolf. In a second we were pumping lead into the pack, but with more excitement than accuracy: how to aim 
a steep downhill shot is always confusing. When our rifles were empty, the old wolf was down, and a pup was dragging a leg into impassable slide-rocks. We reached the old wolf in time to watch a fierce green fire dying in her eyes. I realized then, and have known ever since, that there was something new to me in those eyes - something known only to her and to the mountain. I was young then, and full of trigger-itch; I thought that because fewer wolves meant more deer, that no wolves would mean hunters' paradise. But after seeing the green fire die, I sensed that neither the wolf nor the mountain agreed with such a view. (Leopold 130)

This short paragraph, which depicts the author in his life-changing confrontation with a wolf, shows more than just the scene of a killing. While the procedure of the elimination of the wolf at the first site gives an accurate impression of the widespread mentality of people at the time, a far more intimate moment unfolds here as well. The author sees the animal for the first time as more than a mere predator and enemy, the traditional image of the wolf. In the author's words there is a form of admiration and silent awe when faced with the death of a noble animal - not only due to the situation itself, but also due to the fact that the shooter realizes the role of the animal in the ways of the land, as well as his own role.

The mystery that is the wolf is represented by its omnipresent and faraway howling: "Only the mountain has lived long enough to listen objectively to the howl of a wolf" (Leopold 130). This sound and its hidden message can be only understood by few, but it is known to many: "Those unable to decipher the hidden meaning know nevertheless that it is there, for it is felt in all wolf country, and distinguishes that country from all other land. It tingles in the spine of all who hear wolves by night, or who scan their tracks by day (129)". The presence of the wolf, often represented by the sound of the howl, forms an inseparable part of the land and has great importance, despite man's intention to get rid of this animal for the good of his herds or to encourage an abundance of game, which would at first glance flourish without its chief predator. This is actually the vital information conveyed by the encounter with the wolf in this book - information which changes the author's perspective and urges the reader to ponder this thought in order to understand the mystery of the ecosystem:

I now suspect that just as a deer herd lives in mortal fear of its wolves, so does a mountain live in mortal fear of its deer. And perhaps with better cause, for while a buck pulled down by wolves can be replaced in two or three years, a range pulled down by too many deer may fail of replacement in as many decades. (132)

The conclusion that Leopold draws from this pivotal episode is that the wolves are but one of many pieces in the delicate system of the natural world. They have their role, as has the deer and as have all the other animals. By completely eliminating even one of these species, man would inevitably threaten this complex system, whose full and complete depth is impossible to fathom.

Leopold also warns that meddling with nature, even with the best of intentions, is in fact merely creating more damage further down the line: 
A measure of success in this is all well enough, and perhaps is a requisite to objective thinking, but too much safety seems to yield only danger in the long run. Perhaps this is behind Thoreau's dictum: In wildness is the salvation of the world. Perhaps this is the hidden meaning in the howl of the wolf, long known among mountains, but seldom perceived among men. (133)

Both Aldo Leopold and Henry David Thoreau, to whom Leopold refers in the above-cited lines, claim that wildness is the key and the solution to these problems. And if there is one element of wisdom to be found in and remembered from Leopold's text, it is to hold nature in proper respect, as it is still very much mysterious and unknown (as it was in the past), and as man's hubris would ultimately only backfire on humanity itself should people threaten the ecosystem they inhabit by their colonization of the land.

One author whose work displays certain similarities with Aldo Leopold as far as their life-changing experience with wolves is concerned is Ernest Thompson Seton. Despite being born in England and spending his childhood in Canada, Seton (and especially his work that is examined below) is closely connected to the United States. His book Wild Animals I Have Known (1898) contains one story that has particular significance for the themes discussed in this paper. This is a story entitled "Lobo the King of Currumpaw", which takes place in New Mexico and explores Seton's experience of living in the Currumpaw Valley.

Much like Leopold, Seton presents his readers with the moment when his view of the wolf drastically changed. The story is about Lobo, the leader of the pack, who is forced to prey upon the herds of local farmers when the pack's wild food disappears. Lobo cunningly evades every attempt at capture:

The second day after the traps arrived, I rode around to inspect, and soon came upon Lobo's trail running from trap to trap. In the dust I could read the whole story of his doings that night. He had trotted along in the darkness, and although the traps were so carefully concealed, he had instantly detected the first one. Stopping the onward march of the pack, he had cautiously scratched around it until he had disclosed the trap, the chain, and the log, then left them wholly exposed to view with the trap still unsprung and passing on he treated over a dozen traps in the same fashion. (Seton 39)

Seton finally succeeds in capturing the wolf by catching his mate, the she-wolf Blanca. After killing Blanca in front of Lobo, the pack-leader becomes careless and follows his late mate's scent to the human settlements where he is captured. At this point, however, Seton cannot bring himself to kill his nemesis. It was actually the first time that the hunter properly examined his quarry, and to his shock, Seton realized that Lobo was not the monstrous entity and devilish fiend described by witnesses or imagined by his enemies. He was a proud animal who was defeated not by the hunters, but by his sorrow and longing for his killed mate. Lobo died himself a few days after being captured, refusing to be fed by his captors, and he forever changed Seton's view of the wolf:

A lion shorn of his strength, an eagle robbed of his freedom, or a dove bereft of his mate, all die, it is said, of a broken heart; and who will aver that this grim bandit could bear the three-fold brunt, heart-whole? This only I know, that when the morning dawned, he 
was lying there still in his position of calm repose, his body unwounded, but his spirit was gone-the old king wolf was dead. (53-54)

This sudden change in perspective is all the more powerful given the fact that Seton had at first been so keen on killing the beast. Unlike Aldo Leopold, he was not an unwise youth shooting blindly at the wolf; he systematically and meticulously worked to achieve the animal's downfall. This was one of the most prominent testimonies in defence of wild nature, which found one of its first defenders in the environmentalist writer Ernest Thompson Seton.

Another environmental writer who should be discussed is the already-mentioned Barry Lopez and his of Wolves and Men. In addition to presenting scientific insights into wolves, Lopez explores the mythology and depictions of these animals in various stories, myths and legends which have been retold numerous times down the generations in the cultures of the Old and New Worlds. Lopez categorizes the literary treatment of the wolf into several distinct approaches, some of which will be explored in the following paragraphs, beginning with the early medieval perception of the animal. Lopez argues that the wolf as it is perceived in our literary, oral and cultural traditions is a creation of people's imagination and has very different characteristics from those of the true animal and most importantly, it should be viewed as two different entities and not one:

Each of these visions flows, historically, from man's never-ending struggle to come to grips with the nature of the universe. That struggle has produced at different times in history different places for the wolf to fit; and at the same moment in history different ideas of the wolf's place in the universe have existed side by side, even in the same culture. So, in the wolf we have not so much an animal that we have always known as one that we have consistently imagined. To the human imagination the wolf has proved at various times the appropriate symbol for greed or savagery, the exactly proper guise for the Devil, or fitting as a patron of warrior clans. (204)

Here the question arises: why would the wolf become a symbol of such evil human traits, synonymous with warmongering and all things evil? One of the explanations Lopez presents involves simply tracing this phenomenon further and further back through the history of mankind. The author mentions the Greek mythological tradition and its possible influence on the medieval mind in association with the god Apollo:

At the southern end of the Acropolis in Athens stand the ruins of the Lyceum. Philologists argue about the origin of the name but it seems probable that the building was once used as a place of worship for Apollo, the Wolf Slayer. Apollo was a patron of shepherds, and Pausanias, a second-century Greek author, writes that it was Apollo who directed shepherds to put out meat laced with bark poison to kill wolves. In later years the Lyceum became a gymnasium, then a hall where Aristotle, among others, taught. At the time he was lecturing, Aristotle was writing a text on animals, and in the section on wolves he included the story of Apollo's birth on the Island of Delos. Apollo's mother, Leto, disguised as a wolf and accompanied by a pack of wolves, had made the trip 
from the land of the Hyperboreans to Delos to escape detection by the jealous Hera, wife of Zeus, who was Apollo's father. (Lopez 271-272)

A further intriguing fact about Apollo's role in the Greek pantheon is related to the various interpretations of the god's name; as Lopez says, Apollo was not always mentioned and presented as the wolf slayer. Despite being known mainly as the sun god, the tradition of Apollo in Greek culture and mythology has varied greatly throughout the ages. Lopez argues that one of the possible confusions has arisen from the similarity between the Greek words for "wolf" and "light”, or from the legends of the gods' births, or perhaps the place of the sun god's origin, in Lycea. Nevertheless, Lopez ultimately emphasizes the importance of historical accounts, as the contradictory depictions of Apollo as both the wolf god and the wolf slayer were taken from the worshippers themselves. As Lopez explains, the original totemic tribes that occupied the Peloponnese held strong ties to wolves, and worshipped them in a similar fashion to the old Germanic tribes of Northern and Central Europe or the Native American tribes who also held the spiritual wolf in high esteem. The duality arrived with the invasion of Hellenistic people, who conquered the area and introduced their own culture, forcing the totemic tradition to step aside. The wolf, however, still retained its importance in the culture of these invaders; it is seen as an image of threat and danger to the herd, and since Hellenistic culture was based around the production of sheep and agriculture, the warrior-based imagery of the wolf god Apollo was twisted to suit the needs of the newly arrived population (Lopez 272).

It would seem that the struggle inherent in the dualism of the wolf as represented by the god Apollo was decisively won by the wolf slayer and the protector of the herds, as the medieval portrayal of the wolf is mostly negative; it was viewed as the enemy by farmers and shepherds, but another factor mentioned by Lopez is its role in the representation of the devil, greatly emphasized in numerous religious writings. It seems only logical that if the son of God is the lamb, his natural adversary would be the natural predator to the sheep. Lopez supports this argument with a great number of examples (including Dante's Divine Comedy); here we can clearly see the negative point of view that was omnipresent in the common medieval European's mind:

In the first canto of Dante's Inferno in the Commedia the wolf appears in one of the oldest and most durable associations in its history, as a symbol of greed and fraud. In the eighth circle of Hell, Dante finds those condemned for "the sins of the wolf": seducers and hypocrites, magicians, thieves, and liars. (205)

The European view of the wolf can be even more aptly described by Claudia D. Johnson in her Understanding the Call of the Wild (2000): "So-called science and imperfect observation as well as folklore perpetuated the view of the wolf as an aggressive and fearless devourer of sheep, cows, defenceless men, women, and, especially, children and a grave robber who craved the flesh of dead humans. In Europe, this resulted in the wholesale slaughter of wolves" (Johnson 15). Another important aspect that benefited the medieval Christian Church in its use of the wolf as a symbol of evil is the fact that the wolf had been 
a rather popular figure in many old pagan religions which had been vehemently opposed by Christianity in the past. One of the oldest pagan mythologies that worshipped the wolf in spite of herding large numbers of cattle was that of the Egyptians. Their jackal-headed god of mummification and the dead, Anubis, was one of the most revered Egyptian deities, and remains well-known even today.

However, if there are cultures that both worshipped and respected the imagery of the wolf and were viewed as fierce enemies of the Christian faith prior to the Middle Ages, one would definitely think of the Norse people:

The wolf that shows up in Apollonian legend is one that is familiar to us. The wolf of the Norsemen is something quite different. In that mythology we encounter some elements already familiar: the wolf in association with light, with war, with witches, and with Loki, the trickster. But the wolves of Teutonic mythology are overpowering in these roles. (Lopez 273)

Lopez's discussion of the wolf in Norse myth does not end here; the animal was held in such high esteem that it was depicted in association with the chief figure in Old Norse mythology, the All-father Odin himself:

Nordic wolves were the companions of the Norns, the Teutonic fates. The Finns called them Rutu's hounds, dogs of the death spirit. The ruler of all the gods, Odin, kept two wolves always at his side, Geri and Freki. They accompanied him in battle together with his two ravens, and tore the corpses of the dead. Thus Wolfram, from Wolf-hraben, "wolf-raven", was a great warrior's name, and to see a wolf and a raven on the way to battle augured victory. Rudolf, from Ruhm-wolf, was another warrior name, meaning "victorious wolf". And Wolfgang meant "wolf going before", a hero whose coming was announced by the appearance of wolves. (Lopez 273-274)

But probably the most famous and discussed lupine entity that Lopez places high importance on is the son of Loki, the apocalyptic wolf Fenrir. His story, as is the case with all the stories mentioned above, could easily form the subject of a stand-alone analysis, but one aspect of this myth that Lopez emphasizes is the taming of the wild inside the beast. He argues that the wolf that had been destined to devour Odin, the leader of the gods, was driven to its present state by the gods themselves, who - in their fear of his great and untamed power - sought to bind and control it and thus created its hatred and aggression. To Lopez, the allusion to how the people of Europe, America and the entire civilized world hunted wolves and reduced wolf populations is more than clear. These stark contrasts between the European population's attitude towards the wolf in the Middle Ages and in the times of Old Norse culture can also be viewed in comparison to the already-mentioned situation in America. The wolf population in North America was also revered by the Native Americans and respected for the animals' many qualities, until the colonists arrived and led to the current decline in populations and a radical shift in the portrayal of wolves. Lopez also argues that there is a connection between the downfall of 
wolves in both real and literary terms, as the tradition that worshipped the wolves ceased to exist with the Native American and Viking cultures themselves.

Concluding his historical account of generations of humans' relationship with wolves, both in positive and negative terms, Lopez argues that there is more to the current situation regarding this relationship in America. In two of this pivotal chapters of his book, entitled "An American Pogrom" and "The Clamor of Justification", the text explores more reasons for the systematic elimination of the wolf that occurred throughout the history of America. The first of these reasons is the simple necessity for survival. Lopez elaborates on how the expanding colonies and newly-founded settlements saw the killings as justifiable and necessary actions, whether in the name of survival (initially) or in view of economic factors (later down the road of American history). Lopez also emphasizes that society as a whole was responsible for these systematic killings; in his opinion, it was not only hunters who were to blame. As he explains, wolf-hunting gradually developed into a business in America, and as demand bred supply, both the pelts and the safety created by the absence of the predators were much desired by farmers and other members of the population. Lopez explains that society justified these acts as part of its Manifest Destiny, and saw these actions as a manifestation of the greater good, as they led to the colonists' inevitable domination of the land. This taming of the country and the wolf continued on two levels simultaneously: first consciously, for profit and to safeguard property, and then instinctually, as man asserted his dominance over nature and animals. Lopez also criticizes the layman's approach to these hunts in the following sentences:

Wolves are predators. When men come into a land to "tame" it, they replace wild game with domestic animals. The wolves prey on these creatures, the men kill them in turn, and reduce the wolf population generally, as a preventive measure to secure their economic investment. The two just can't live side by side. A step removed from this, perhaps, in terms of its justification, is the action of Fish and Game departments that kill wolves to sustain or increase the yield of big game animals so human hunters can kill them. This kind of "predator control" has historically accommodated economic and political interests ahead of ecological interests. And it has acted occasionally from a basis of bar stool and barbershop biology, not wildlife science. (Lopez 138-139)

Lopez also studies the economic side of these events, noting a number of occasions when such deeds were done not for profit, but for entirely different reasons. The regular trappers and bounty hunters killed the animals solely for profit, either from selling the pelts, or from the bounties offered by the local authorities. Less frequent, but still quite common reasons for hunting were scientific studies conducted in order to learn more about the animals, their behaviour and more. Wolves were sometimes shot and then dissected, or caught and experimented upon in order to improve future "predator control expeditions". It was not rare to hunt for wolf pups, as they were seen in the same light as the mature specimens. 
Lopez also gives far more detailed descriptions of such actions, as his intention is to shock the reader by revealing the true nature of these hunts to the fullest extent. He claims that out of the two reasons for the hunts (conscious and instinctual), the latter had a tendency to predominate the longer these wolf killings dragged on:

Indeed, this is the way we commonly treat all predators-bobcats, bears, and mountain lions included. But the wolf is fundamentally different because the history of killing wolves shows far less restraint and far more perversity. A lot of people didn't just kill wolves; they tortured them. They set wolves on fire and tore their jaws out and cut their Achilles tendons and turned dogs loose on them. They poisoned them with strychnine, arsenic, and cyanide, on such a scale that millions of other animals-raccoons, black-footed ferrets, red foxes, ravens, red-tailed hawks, eagles, ground squirrels, wolverines-were killed incidentally in the process. (139-140)

But these animals were not the only ones that sustained collateral damage. The perpetrators of the hunts themselves were sometimes caught in the crossfire of their own actions. Lopez mentions cases when the hunters accidentally poisoned their own pets or water supplies, or other times when they burned down scores of houses as a result of their attempts to burn out sections of the forests inhabited by wolves. Lopez goes as far as to call this state of mind "wolf fever"; he claims that it reached its peak in the United States between 1865 and 1885. During that period, farmers and cattlemen eradicated wolves with almost pathological zealotry. There were claims that every hunt during which even the slightest signs of wolves' presence were found should immediately become wolf hunts. Later on, many people dragged still-living wolves behind their airplanes and snowmobiles in order to prolong their suffering, and they sometimes kept these cadavers as a display of masculinity that was not so different from tribal warrior trophies. Another case involved shooting tied-up wolves with a shotgun just for sport, long after their capture, and it was not until the 1970s that Minnesota added the wolf to its list of endangered species. Needless to say, the majority of the population ignored these regulations, and there are even documented accounts of timber wolves being choked to death in snares as a form of protest against this news. These stories could be recounted at much greater length, as there is an ample supply of them both in history and in Lopez's text.

These drastic measures would be shocking enough in a few pathological cases, but they were far from isolated; according to Lopez, these practices are still very much alive among a majority of the population. So naturally, here the question arises: what led people to possess such a savage dedication to killing wolves, even in the $20^{\text {th }}$ century, that American society not only turned a blind eye to such practices, but openly expressed its approval? In Lopez's opinion, it all comes back to the already-mentioned wild side, our inner instincts, which are ignored by civilization, so people once again seek to take control of the reins in the wild way:

This is not predator control, and it goes beyond the casual cruelty sociologists say manifests itself among people under stress, or where there is no perception of responsibility. It is the violent expression of a terrible assumption: that men have the right to 
kill other creatures not for what they do but for what we fear they may do. I almost wrote "or for no reason", but there are always reasons. Killing wolves has to do with fear based on superstitions. It has to do with "duty". It has to do with proving manhood (abstractly, perhaps, this is nothing more than wanting either to possess or to destroy the animal's soul). And sometimes, I think, because the killing is so righteously pursued and yet so entirely without conscience, killing wolves has to do with murder. (140)

Lopez also mentions the scientific terminology related to the psychological side of this topic, with special focus on the term theriophobia - the fear of the beast. In a way, this phobia is unlike any other, because its focus varies depending on what precisely its victims fear. In the case of theriophobia, we have an irrational fear of wild creatures such as wolves, which stir our deepest and most violent instincts as a form of defence mechanism. However, since the fear itself is irrational and in many cases is based on no real threat, the wrath unleashed by people upon presumed predators and enemies is in no way justifiable. And as Lopez states, it is precisely this wild phenomenon that carries part of the blame for the most horrendous atrocities in human conflicts. Simply put, the rapes, murders and the pillaging that take place in wartime can often be rooted in the same soil as the needless torture and hunting of wolves. The unfortunate prime target of theriophobia in America, the wolf, then became, in the opinion of Barry Lopez, the ultimate scapegoat which needed to be annihilated. However, do we truly become more noble, higher, dignified, "civilized" in this way? Many of these wolf-hunters became quite the opposite; they became more feral, and wilder in the process. To Barry Lopez, who seeks to enlighten his readers and society as a whole on this matter, it seems rather absurd that there should be any attempt to vanquish the evil of the beast by committing bestial acts, while the simplest of facts is ignored - namely that the real wolf and the wolf we have created are two different entities.

\section{[4] The dichotomy of the wolf}

Another writer who shares some viewpoints with Barry Lopez, but also differs from him on some topics and so brings a fresh perspective to this investigation - is S.K. Robisch, the author of Wolves and the Wolf Myth in American Literature (2009). This work is a thorough investigation of wolves in mythology and reality in America; it also focuses on the work of many other writers. Robisch takes a more neutral position than Lopez, and expresses a more varied range of opinions. One of the most intriguing parts of the work is a chapter from the so-called "Wolf Book" section of the text - "The Real, the Corporeal, and the Ghost Wolf". As the name suggests, Robisch, much like Lopez in his Of Wolves and Men (1979), differentiates between different types of wolves in the world. But while Lopez focuses on the real wolf and the imaginary one, Robisch offers more variety in the categorization.

Starting with the simplest concept to grasp, we have the "Real Wolf". In the words of Robisch: 
The Real Wolf. There is, indeed, such a being as a wild wolf. He is not a social construct. She is not a figment of the human imagination. Neither are they mere progenitors of the dog, nor is their collective life reducible to a selective and solipsistic riffing about whether or not wilderness, wildness, animals, or authors exist. The idolization of idealism over materialism had done them no good, idealism being no more defensible a position than materialism; in situations of ecological reference versus anthropocentric reference, materialism is almost always the more practicable philosophical mode. (34)

Robisch claims that although wolves have lived along the human population throughout the whole history of mankind, these animals were never of human design, as some may subconsciously believe. That is to say, we still do not know all there is to be known about these animals, yet we write about them as if we did. This reality stands in direct opposition to the common anthropocentric mentality present not only in man's everyday life, but especially in writings about wolves. Robisch emphasizes the incredible levels of individuality present in wolves; they are not only individuals within their respective packs, but they are also a species with a great variety of subspecies (as has been discussed in the first part of this paper). According to Robisch, the only logical outcome is that the wolf is an animal that cannot ever be fully captured in its true form by writing. Indeed, the written representation of wolves differs depending on the field and style of the text, ranging from fiction to scientific writings based in biology or ecology. In the author's words, "Real wolves are not texts; they are the corrective entities to the texts attempting to depict them" (34).

Robisch also claims that despite the best intentions of their authors, many ecocritical writings cause even more damage. Robisch mentions the danger of idealization, which can be mitigated by adopting more materialistic and realistic stances, as such stances have far better chances of initial acceptance by society, which will ultimately lead to the desired understanding of the topic.

The introductory text on the Real Wolf continues in the same manner until it reaches the crucial concept of the World-Wolf.:

The World-Wolf. This is the form that embodies all the various representations of wolves in literature. I am borrowing the name from the myth of Fenris in the Icelandic story of the end of the world and the dawn of a new humanity, as well as from the concept of the anima mundi. The World-Wolf is therefore nor the real or earthly wolf, but the "wolf" of a word of our invention, a symbolic figure shaped according to our own desires - for prowess, material, nurture, conquest, or identity, our placement in the cosmos. Here is idealist component in relation to the materialist component. This World-Wolf may be configured as the Nietzschean überwolf, the Emersonian transcendental Over-Wolf, or the platonic form of Wolf-including their potential misuses. (Robisch 35)

Robisch goes to great lengths to properly define the correct terminology and discusses various aspects of the entity of the World-Wolf. He divides this term into the Corporeal Wolf and the Ghost Wolf (with both Malevolent and Benevolent facets) and discusses the so-called Lines, which delineate boundaries for these terms depending on the context. 
The Corporeal Wolf, according to Robisch, is the real wolf that literature attempts to depict as it is. As Robisch is convinced of the impossibility of such a feat, we are left with a term that is more or less synonymous with many "real" wolves as ecocritical writers (including Lopez for instance) portray them. Robisch points out that there should be no acceptance of blind idealism, as the very nature of humans - and by extension, their writings - is that they are victims of time and change. What used to be set and well-established knowledge may be frowned upon a hundred years later - whether by scientific opinion or by society as a whole. And while this self-corrective approach does inevitably bear fruit in the form of more accurate and reliable information, the author remains adamant in his belief that no information is absolute, but rather scalar - enabling people to account for future surprises and new discoveries.

The second facet of the World-Wolf is somewhat more complex than the first; from the beginning, Robisch warns of its dual nature. To comprehend this dualistic character of the Ghost Wolf concept, we first must understand what the concept refers to. This key entity, which is very similar to Lopez's imaginary wolf, is the sum of all the man-created depictions and portrayals of the animal, both positive and negative. This brief extract will provide more clarification and understanding of this duality:

The Ghost Wolf. I use the term ghost as an indicator of two historical phenomena. First is the overwhelming presence in human culture of myth and its totemic, ethereal, unconscious, and symbolic images, including the undeniable presence of imaginary animals in our mythologies; the second is the effort in both Europe and America to eradicate the wolf from the face of the earth, leaving its revenant shade in its former regions. I could call this "the imaginary wolf", but "ghost" offers a more appropriate frisson, given what's happened to wolves in America and in its literature. A better synonym might be "the shadow wolf", one that will have especial application in the more Jungian moments of this study. (Robisch 37-38)

Robisch then describes the two identities of this ghost, both positive and negative, and labels them the Benevolent Ghost and the Malevolent Ghost respectively. While the negative imagery has done unspeakable harm to the reality of these animals and is arguably one of the chief reasons for their slaughter, the positive propaganda does them no more good than its negative counterpart.

The chapter then once again deals with a topic that has already been discussed, i.e. how the colonists imported their grudge against wolves from the Old World. In doing so, they even influenced scientific opinions, so that wolf pogroms were carried out with the blessing of the state; as has already been mentioned, this was done via the governmental wildlife "management" policies that aimed to protect the ecological balance. However, ironically, it was precisely this wildlife management policy that brought wolves (and in some cases also other animals) to the point of extinction.

As far as the Benevolent Ghost is concerned, Robisch compares this creation to that of the noble-savage or ecotopian idealism - which is as far from reality as the previous example was. The main target of his criticism in this case is not the beatification of the 
noble traits in the animals, of their intelligence, social behaviour, wisdom and importance to the land, but rather people's blindness and ignorance towards the danger, the ferocity, the territoriality and even the rare and isolated cases of unprovoked aggression from wolves (there can be deranged individuals in the wolf world, just as there are in ours), which are all still real as well.

Finally, Robisch discusses his concept of the "Lines". Highlighting once again the scalar nature of the world, he notes that this notion of scalar "Lines" stems from the fact that all the wolves we encounter in literature, in the news and in legends, in nature and in our own imagination, should be perceived with the utmost care; readers should keep in mind that absolutes are rare and nothing is black or white, that there are boundaries, the "Lines" to be noted and respected.

\section{[5] Conclusion}

The main aim of this paper was to discuss the portrayal of the wolf in literature. The paper has addressed various views and tendencies in American literature of the $20^{\text {th }}$ and $21^{\text {st }}$ centuries. As the paper reveals, a considerable change in people's perceptions of this animal has occurred during these two centuries. From highly negative and hateful standpoints, the public gradually discovered the mysterious side of the wolf. Both environmentalist writers and fiction writers began to portray the wolf not as an antagonist, but as a representative of wild, untamed nature - a phenomenon which is becoming so rare in the present day. However, this evolution also involves ideologies which are overly romanticized and misinformed, and which may ultimately cause harm.

The paper presents a considerable amount of information about the wolf in American literature, yet it only begins to unravel the underlying reality. For this reason, the wolf - both in fiction and in real life - should be approached with critical distance in order to understand it as much as possible without harming it or oneself. The tendencies in American environmental literature that has approached this topic are varied, and in the $20^{\text {th }}$ and $21^{\text {st }}$ centuries they have encompassed a plethora of writers with various perspectives, ranging from philosophical, novelistic, essayistic and descriptive to defensive to the point of being biased. All have their own merits when examining the topic, leading this paper to the conclusion that the wolf in America is both a predator and scapegoat and yet still so much more.

\section{[Bibliography]}

Ehrlich, Gretel. The Solace of Open Spaces. New York: Penguin Books, 1986.

Johnson, Claudia Durst. Understanding the Call of the Wild. Westoport, CT.: Greenwood Press, 2000.

Leopold, Aldo. A Sand County Almanac: And Sketched Here and There. Oxford, New York: Oxford University Press, 1989.

London, Jack. The Call of the Wild. New York: HarperCollins Publishers, 2011. 
---. White Fang. New York: HarperCollins Publishers, 2014.

Lopez, Barry. Of Wolves and Men. New York: Charles Scribner's Sons. 1979.

McCarthy, Corcmac. A Cormac McCarthy Companion: The Border Trilogy. Jackson: University Press Mississippi, 2001.

Robisch, S.K. Wolves and the Wolf Myth in American Literature. Reno: University of Nevada Press, 2009.

Sanborn, Wallis R. "I Aint Heard One in Years": Wolves as Metaphor in "The Crossing". In S. Peebles (Ed.) Cormac McCarthy Journal (pp. 25-37). State College: Penn State University Press, 2003.

Seton, Ernest Thompson. Wild Animals I Have Known. New York: Charles Scribner's Sons, 1898.

Snyder, Gary. The Practice of the Wild. San Francisco: North Point Press, 1990.

[Address]

Department of English and American Studies

Faculty of Arts

University of Ostrava

Reální 5

70103 Ostrava

Czech Republic

pavel.sef@gmail.com

Pavel Šefraný is a Master's degree student of Teaching for Secondary Schools - English and Spanish languages and literature at the University of Ostrava. Apart from literature and teaching, his major fields of interest include the history of England and Spain and the representation of their myths in contemporary literary and cinematographic works. 